\title{
Promoter methylation in the $\mathrm{PTCH}$ gene in cervical epithelial cancer and ovarian cancer tissue as studied by eight novel Pyrosequencing ${ }^{\circledR}$ assays
}

\author{
ZARAH M. LÖF-ÖHLIN ${ }^{1}$, SONJA LEVANAT ${ }^{3}$, MAJA SABOL $^{3}$, BENGT SORBE ${ }^{2}$ and TORBJÖRN K. NILSSON ${ }^{1,4}$ \\ Departments of ${ }^{1}$ Laboratory Medicine, Clinical Chemistry, and ${ }^{2}$ Gynecological Oncology, Örebro University Hospital, \\ Örebro, Sweden; ${ }^{3}$ Division of Molecular Medicine, Rudjer Boskovic Institute, Zagreb, Croatia; \\ ${ }^{4}$ Department of Biomedicine, School of Health and Medical Sciences, Örebro University, Örebro, Sweden
}

Received September 27, 2010; Accepted November 15, 2010

DOI: $10.3892 /$ ijo. 2011.895

\begin{abstract}
DNA methylation status in the CpG sites of promoter regions in cancer-related genes, such as $\mathrm{PTCH}$, has traditionally been investigated using either dye-terminator sequencing or methylation-specific PCR. We aimed to study the $P T C H$ gene promoter methylation in gynecological cancers, with a method that gives a quantitative measure of the methylation status of the promoter region of the studied gene, and for this purpose, we designed novel Pyrosequencingbased assays. Bisulfite-treated genomic DNA (bsDNA) was amplified by standard PCR and applied to novel Pyrosequencing ${ }^{\circledR}$ assays, in order to measure the methylated fraction (\%) at each CpG site of the $P T C H$ gene promoter. We analyzed 22 squamous cell cervical cancer tissue specimens (11 with good and 11 with poor outcomes after radiotherapy) and 5 ovarian cancer tissue specimens matched with 5 normal ovarian tissue specimens. Six optimized PCR protocols which generated 8 Pyrosequencing assays covering $63 \mathrm{CpG}$ sites in the promoter regions 1 and 2 as well as the previously unanalyzed promoter region 3 in the $P T C H$ gene were developed. The 27 tumor tissue specimens and 5 normal tissues did not show any methylation within any of the $63 \mathrm{CpG}$ sites. Our data suggest that methylation of the $P T C H$ promoter is not a high-prevalence feature of squamous cell cervical cancer or ovarian cancer, but Pyrosequencing assays are a good method for studying promoter methylation.
\end{abstract}

\section{Introduction}

The Patched gene $(\mathrm{PTCH})$ is involved in the Hedgehog/Patched signaling pathway and is known to play a role in mammalian

Correspondence to: Dr Sonja Levanat, Division of Molecular Medicine, Rudjer Boskovic Institute, Bijenicka 54, 10002 Zagreb, Croatia

E-mail: levanat@irb.hr

Key words: CpG sites, DNA methylation, Hedgehog pathway, Pyrosequencing technology development and in regulation of stem cell renewal in adult tissue (1). PTCH is a major pathway receptor localized to the plasma membrane that moves to the endocytic vesicles upon ligand binding $(2,3)$, where the ligand could be either Sonic (SHH), Indian (IHH) or Desert Hedgehog (DHH). PTCH associates with the Smoothened protein (SMO) and inhibits downstream targets such as PTCH, GLII, HIP and TGF- $\beta$ (4) in the absence of ligand. PTCH activity is repressed and SMO is activated if SHH is present. This activity leads to the translocation of the GLI protein to the nucleus and transcription of downstream targets (5).

Alterations in this pathway such as phenotypical changes of the proteins involved because of mutations of the genes $(2,6)$, or dysregulation of the genes because of aberrant methylation patterns of their promoter regions $(7,8)$, can alter carcinogenic transformation.

PTCH is expressed in the adult human kidney, liver, lung, brain, heart, placenta, skeletal muscle and pancreas (9). It has been suggested that the PTCH gene has tumor-suppressor function because it appears to be involved in the development of several cancers such as ovarian dermoids, fibromas (7), medulloblastoma (10), acute myeloid leukemia (11), uterine cervical carcinoma (12), breast cancer (8), sporadic basal cell carcinomas (13) and nevoid basal cell carcinoma (2).

Epigenetic regulation, through methylation or demethylation of $\mathrm{CpG}$ sites in promoter regions of cancer-related genes by methyltransferases (14), plays an important role in the pathogenesis of cancer (15). This mode of regulation can be considered activating or silencing depending upon action. PTCH has several alternative splicing sites (a, b, c, d and e) starting from exon $1(16,17)$. The most studied of these regions, in relevance to epigenetic changes and regulatory effects of the protein $(7,8,12)$, contains the $\mathrm{N}$-terminus encoded by exon $1 \mathrm{~B}(16,18)$. This particular variant is known to have full inhibitory activity on SMO (18). Recent data suggest an enhanced expression of the PTCH protein in squamous cell carcinoma of uterine cervix and its precursor lesions (12). To link this finding to possible changes in methylation status of the promoter regions of $P T C H$, in response to ovarian cancer development, is an overarching goal of our current $P T C H$ studies using dye-terminator sequencing. Recent findings provide evidence of hypermethylation within the 1600-bp 
long PTCH gene promoter (7), which was divided into four large overlapping contigs. Results were generated from regions 1, 2 and 4; however, region 3 was found to be unfeasible to amplify (7). Dye-terminator sequencing generates a qualitative assay output (presence or absence of methylation); therefore, it is considered limited. This methodology is also generally considered more labor intensive and more costly than other DNA methylation analysis techniques.

Our goal in the present study was to dissect the promoter region of the $\mathrm{PTCH}$ gene into a larger number of short amplicons, in order to investigate the methylation status of the $\mathrm{CpG}$ sites in region 3 that have not yet been studied. In addition, we aimed to quantitatively determine the methylated fraction of the remainder of the $\mathrm{CpG}$ sites in the promoter region of the $\mathrm{PTCH}$ gene (Fig. 1). Therefore, we designed new bisulfite-specific PCR (bs PCR) primers and new Pyrosequencing assays to quantify the methylated fraction of $63 \mathrm{CpG}$ sites contained within the promoter region of the $P T C H$ gene. The assays were applied to a clinical sample of cervical cancer tissues, selected from patients with poor or good prognosis respectively, and to a sample of ovarian cancer tissues with matching normal ovarian tissue controls.

\section{Materials and methods}

Subjects. EDTA blood plasma samples from our routine laboratory were de-identified and used to optimize methods to study the methylation status of selected $\mathrm{CpG}$ sites in exon $1 \mathrm{~b}$ in the promoter region of the $P T C H$ gene. According to Swedish Research Ethics Law on anonymized samples for method development purposes, informed consent was waived for these samples. The novel methods were subsequently used in two clinical studies: a) 22 squamous cell cervical cancer tissue specimens obtained before start of primary radiotherapy of which 11 were from women with a poor prognosis (recurrence of cervical cancer after radiotherapy) and the other 11 from women with a good prognosis (no recurrence of cervical cancer after radiotherapy). The two groups were $100 \%$ matched for tumor stage. The Regional Ethics Committee in Uppsala approved the Swedish part of the study (Act No. 2008/089, 25th june 2008, Uppsala, Sweden); b) 5 de-identified ovarian tumour tissue specimens and 5 normal ovarian tissue specimens from the same patients (kindly provided by Dr S. Oreskovic, Zagreb University Hospital).

The Ethics Committee of the University Hospital Centre Zagreb, Department of Gynaecology and Obstetrics and School of Medicine University of Zagreb on March 1st, 2006 gave statement on approved protocols for genetic research on clinical samples from Department of Gynecology and Obstetrics (Act No. 021-1/49-2006, Zagreb, Petrova 13).

DNA isolation and bisulfite treatment. Genomic DNA (gDNA) was extracted in three different ways. Either from $200 \mu 1$ whole EDTA blood using a BioRobot EZ1 (Qiagen Inc., Valencia, CA, USA) with the QIAamp EZ1 DNA blood $200 \mu 1$ kit according to the manufacturer's instruction (Qiagen), otherwise from squamous cell cervical cancer tissue pieces using the QIAamp DNA Mini Kit (Qiagen) or from ovarian cancer tissue pieces using standard phenol-chloroform method.
In the latter method, all samples were first digested in buffer $(0.9 \%$ Tween-20, $0.9 \%$ Triton X-100, 5 mmol/1 EDTA, $2 \mathrm{mmol} / \mathrm{l}$ DTT, $10 \mathrm{mmol} / \mathrm{l}$ TrisHCl pH 7.5) and proteinase $\mathrm{K}(20 \mu \mathrm{g} / \mathrm{ml})$ overnight at $55^{\circ} \mathrm{C}$.

Approximately $1000 \mathrm{ng}$ freshly extracted DNA was used for the bisulfite treatment. The bisulfite treatment was performed with the EZ DNA Methylation kit according to the manufacturer's instructions (Zymo Research, Orange, CA, USA); however, the incubation time was shortened to $10 \mathrm{~h}$ if the DNA originated from tissue and not from blood. In summary, DNA was diluted with M-Dilution buffer and incubated for $15 \mathrm{~min}$ at $37^{\circ} \mathrm{C}$. CT conversion reagent was added to the DNA samples from the previous step and incubated again at $50^{\circ} \mathrm{C}$ for $16 \mathrm{~h}(10 \mathrm{~h}$ if the DNA originated from tissue). Finally, the samples were incubated on ice for $10 \mathrm{~min}$ and then M-Binding buffer was added. The samples were centrifuged and then washed with M-Wash buffer. The bsDNA was eluted in $10 \mu 1 \mathrm{M}$-Elution buffer and then diluted 5 times with TE buffer $(10 \mathrm{mmol} / \mathrm{l}$ Tris- $\mathrm{HCl}, 0.05 \mathrm{mmol} / \mathrm{l}$ EDTA, pH 7.5).

bs PCR. PCR primers for Pyrosequencing were designed using Methprimer (http://www.urogene.org/methprimer/ index 1.html). Primer sequences can be found in Table I. The objective of the PTCH-gene-PCR primer design was to amplify the same area and same $\mathrm{CpG}$ sites as previously studied by Cretnik et al (7). We chose to shorten the amplicons to be able to perform Pyrosequencing analysis of the $\mathrm{CpG}$ sites, a technique where $\sim 150-200$ bp is the optimal amplicon length (19). The PCR primers would also be uniquely designed and devoid of $\mathrm{CpG}$ sites in primer-binding areas such that amplification will always take place independent of methylation status. This is also known as bisulfite-specific PCR (bs PCR). We utilized the same numbering scheme of $\mathrm{CpG}$ sites as reported by Cretnik et al (7) and as shown in Table I and Fig. 1.

PCR was performed using an Eppendorf Mastercycler (Eppendorf-Netheler-Hinz GmbH, Hamburg, Germany) and the HotStarTaq DNA polymerase Kit (Qiagen); we used 30 or $60 \mu 1$ volume reactions depending on the number of amplicons required to analyze in the Pyrosequencer (PSQ 96MA system, Biotage $\mathrm{AB}$ ). Each reaction contained $0.4 \mu \mathrm{mol} / \mathrm{l}$ of each primer, $1.25 \mathrm{U}$ of Taq polymerase, $1.5 \mathrm{mmol} / 1 \mathrm{MgCl}_{2}$ and $0.2 \mathrm{mmol} / \mathrm{l}$ each of dGTP, dATP, dTTP and dCTP. Five $\mu 1$ of the diluted bisulfite-treated gDNA served as the PCR template. The PCR program consisted of an initial polymerase activation step at $95^{\circ} \mathrm{C}$ for $15 \mathrm{~min}$ followed by 53 cycles of denaturation at $94^{\circ} \mathrm{C}$ for $30 \mathrm{sec}$, primer annealing at $48-57^{\circ} \mathrm{C}$ for $30 \mathrm{sec}$ and extension at $72^{\circ} \mathrm{C}$ for $1 \mathrm{~min}$. A final extension step at $72^{\circ} \mathrm{C}$ for $7 \mathrm{~min}$ finalized the program. The PCR primers, annealing temperatures and amplicon sizes for Pyrosequencing are shown in Table I.

Pyrosequencing. To quantify site-specific methylation, PCR products from the bisulfite-treated genomic DNA samples were analyzed with Pyrosequencing technology; the sequence primers are summarized in Table I. The post-PCR (see above) samples were prepared with the Vacuum Prep Workstation (Biotage AB, Uppsala, Sweden) according to the following protocol summary: $30 \mu 1$ of the amplicon, $3 \mu 1$ Streptavidin 


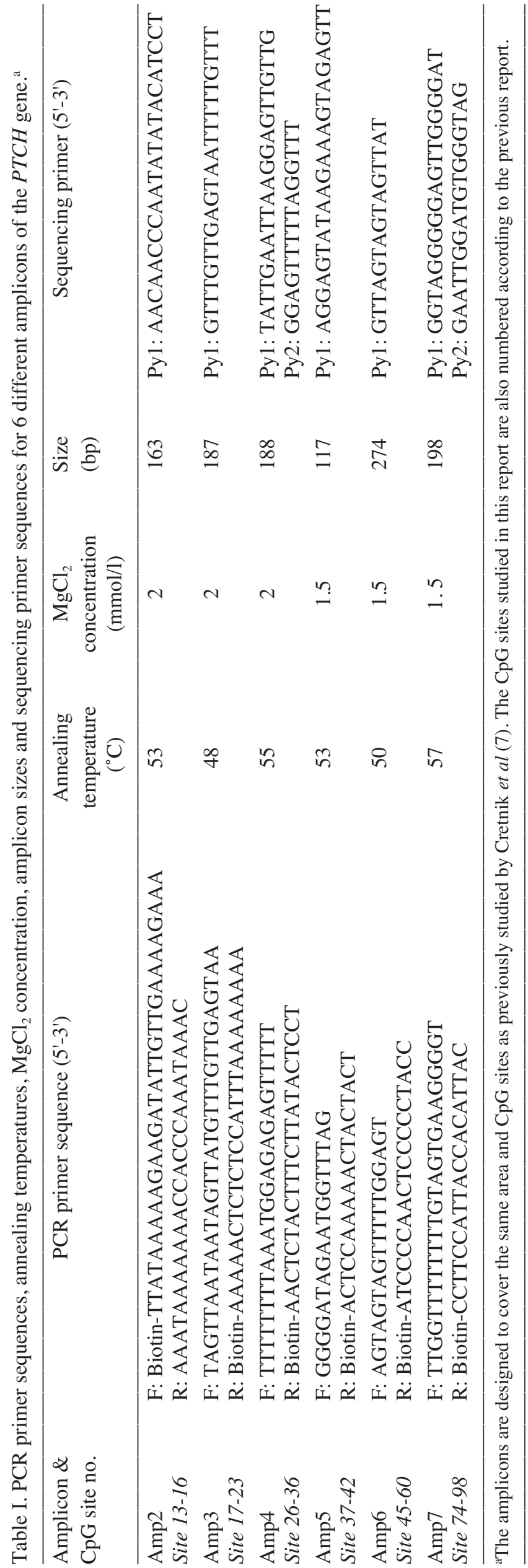

Sepharose HP Beads (Amersham Biosciences, Uppsala, Sweden), $37 \mu 1$ binding buffer (10 mmol/l Tris-HCl, $2 \mathrm{M} \mathrm{NaCl}$, $1 \mathrm{mmol} / 1$ EDTA, $0.1 \%$ Tween-20, Milli-Q (18.2 $\mathrm{M} \Omega \times \mathrm{cm})$ water, $\mathrm{pH}$ 7.6) and $15 \mu 1$ Milli-Q water were mixed and used in the Vacuum Prep workstation. The biotinylated amplicons were immobilized onto the Streptavidin sepharose beads and then passed through one denaturation step and two washing steps using the Vacuum Prep Workstation. The first step was $70 \%$ ethanol, the second $0.2 \mathrm{~mol} / 1 \mathrm{NaOH}$ (denaturation step) and the third was washing buffer $(10 \mathrm{mmol} / \mathrm{l}$ Tris-Acetate, Milli-Q water). The amplicons were transferred to a plate containing sequencing primer $(0.4 \mu \mathrm{mol} / \mathrm{l})$ in $40 \mu \mathrm{l}$ annealing buffer $(20 \mathrm{mmol} / \mathrm{l}$ Tris-acetate, $2 \mathrm{mmol} / \mathrm{l}$ magnesium acetate, $\mathrm{pH}$ 7.6). The sequencing primer was annealed to the template at $80^{\circ} \mathrm{C}$ for $2 \mathrm{~min}$. Pyrosequencing was performed using the PSQ96 SNP Reagent Kit and the PSQ 96MA system (Biotage $\mathrm{AB})$. Pyrograms showing the nucleotide addition order can be seen in Figs. 2-7. Pyro Q-CpG ${ }^{\mathrm{TM}}$ Software v. 1.0.9 was used to determine the optimal order of nucleotide addition, when designing the assays. The software also automatically analyzed the methylation results. The $\%$ methylated fraction $(\mathrm{C} / \mathrm{T}$ ratio) is displayed in a small colored box just above each $\mathrm{CpG}$ site in the analyzed sequence (Figs. 2-7). Each site is analyzed as a C/T-polymorphism where a $100 \% \mathrm{C}$-reading denotes a fully methylated $\mathrm{C}$ in the original gDNA sample and a $100 \%$ T-reading denotes that this $\mathrm{C}$ was unmethylated in the gDNA. Intermediate $\mathrm{C} / \mathrm{T}$ percentages denote partial methylation at the level of the sample.

\section{Results}

Our goal was to develop quantitative methods to measure the methylated fraction of the $\mathrm{CpG}$ sites in the promoter region of the $P T C H$ gene without resorting to 'methylation specific' PCR. In addition, we specifically wanted to develop methods to investigate the unstudied region three of the $P T C H$ promoter [Fig. 1 by Cretnik et al (7)]. We designed six new, shorter, amplicons that were all successfully amplified using conventional PCR with bisulfite treated gDNA as template (Table I).

We also created eight Pyrosequencing assays (Table II) that quantitatively analyzed $63 \mathrm{CpG}$ sites (Figs. 2-7) in regions 1 (Fig. 1, lines 1-6 in ref. 7) and 2 (Fig. 1, lines 6-10 in ref. 7), which have been previously studied by another technique (7), and in addition we covered region 3 (Fig. 1, lines 9-15 in ref. 7) that had been previously unfeasible to study using dye-terminator sequencing (7). Table II displays the length of the PCR amplicons, how many CpG sites they cover and which of these are analyzed in our Pyrosequencing assays. Amplicons 4 and 7 are analyzed using two different Pyrosequencing assays each, whereas the others are covered using one assay each. The amplicon 7 assay includes $25 \mathrm{CpG}$ sites, of which 19 are unique, while six of the analyzed $\mathrm{CpG}$ sites overlap with the last six $\mathrm{CpG}$ sites covered by the amplicon 6 assay, providing a useful internal check of the validity of results. In 96 steps, the Pyrosequencing assay, Amp6-Py1, analyses $16 \mathrm{CpG}$ sites, which is rather unique, not only for this method, but also for methylation analysis in general (Fig. 6).

All the eight assays were applied to two clinical study groups comprising a total of 32 tissue samples. One sample 


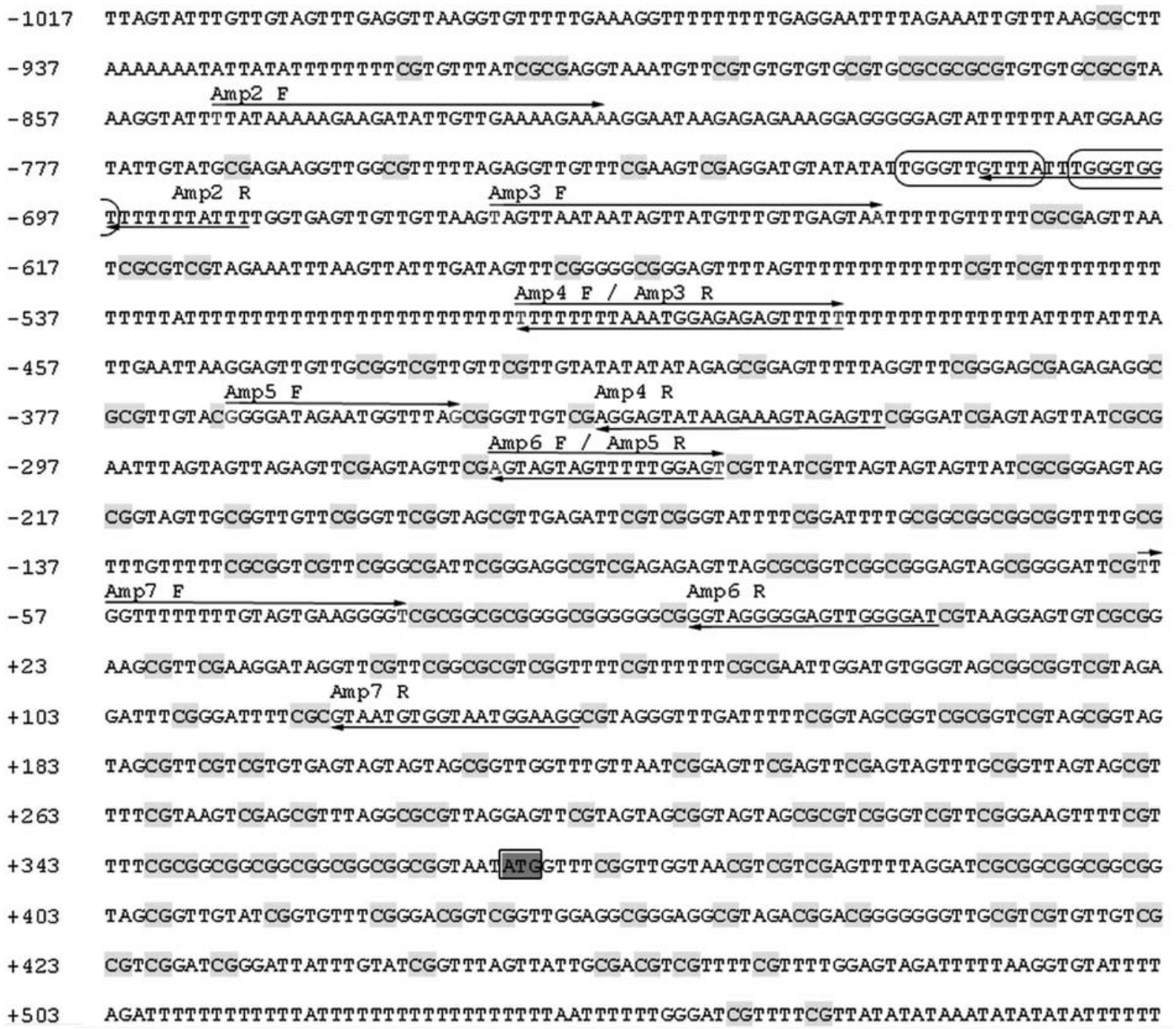

Figure 1. DNA sequence of the analyzed region of the $P T C H$ promoter. The sequence here is shown after bisulfite conversion in which hypothetically all non$\mathrm{CpG}$ sites cytosines are replaced with thymines, whereas cytosines within the $\mathrm{CpG}$ sites remain as cytosines. The forward and reverse primers (marked by arrows) indicate the analyzed regions. The shaded boxes mark all the $164 \mathrm{CpG}$ sites counted from the first (no. 1) in the figure to the last (no. 164) spread throughout the $\sim 1600$-bp long promoter. Gli-binding sites are marked with circles and ATG is in a square.

Table II. Amplicon sizes, number of $\mathrm{CpG}$ sites in the templates, designation of Pyrosequencing assays and number of $\mathrm{CpG}$ sites analyzed for 6 different amplicons of the $P T C H$ gene.

\begin{tabular}{lcccc}
\hline $\begin{array}{l}\text { PCR } \\
\text { amplicon }\end{array}$ & $\begin{array}{c}\text { Amplicon } \\
\text { length (bp) }\end{array}$ & $\begin{array}{c}\text { No. of CpG sites } \\
\text { in the template }\end{array}$ & $\begin{array}{c}\text { Designation of the } \\
\text { Pyrosequencing assays }\end{array}$ & $\begin{array}{c}\text { No. of CpG sites analyzed } \\
\text { by the assay }\end{array}$ \\
\hline Amp2 & 163 & 4 & Amp2-Py1 & 4 \\
Amp3 & 187 & 9 & Amp3-Py1 & 7 \\
Amp4 & 188 & 11 & Amp4-Py1 & 4 \\
& & & Amp4-Py2 & 7 \\
Amp5 & 117 & 8 & Amp5-Py1 & 6 \\
Amp6 & 274 & 25 & Amp6-Py1 & 16 \\
Amp7 & 198 & & Amp7-Py1 & 13 \\
& & & Amp7-Py2 & 6 \\
\hline
\end{tabular}

consisted of 22 squamous cell cervical cancer tissue specimens, from two groups of women: 11 with a poor prognosis (had recurrence of cervical cancer after primary radiotherapy) and 11 from women with a good prognosis (no recurrence of cervical cancer after radiotherapy). The other comprised five ovarian cancer tissues and five normal ovarian tissue 


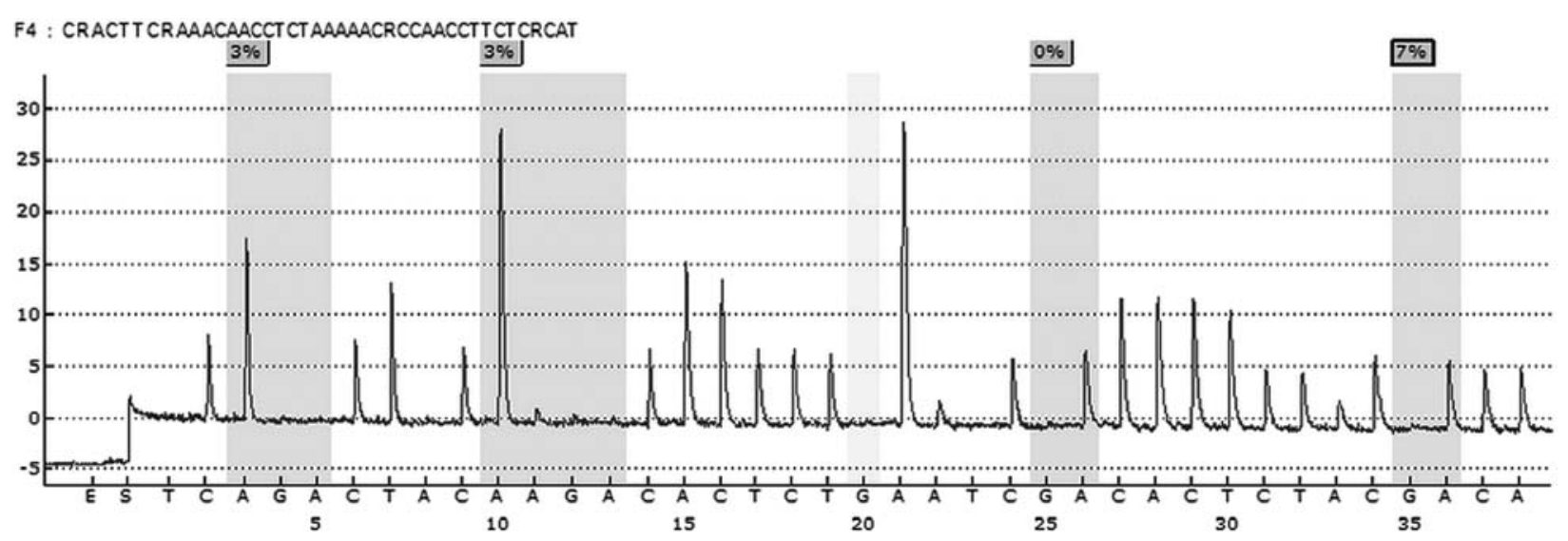

Figure 2. Typical pyrogram showing the sequence analyzed in Amp 2 in the PTCH gene by the Amp 2-Py1 assay. The G base added at nt 20 (lighter grey background) is a negative control to ascertain good bisulfite conversion of the sample.

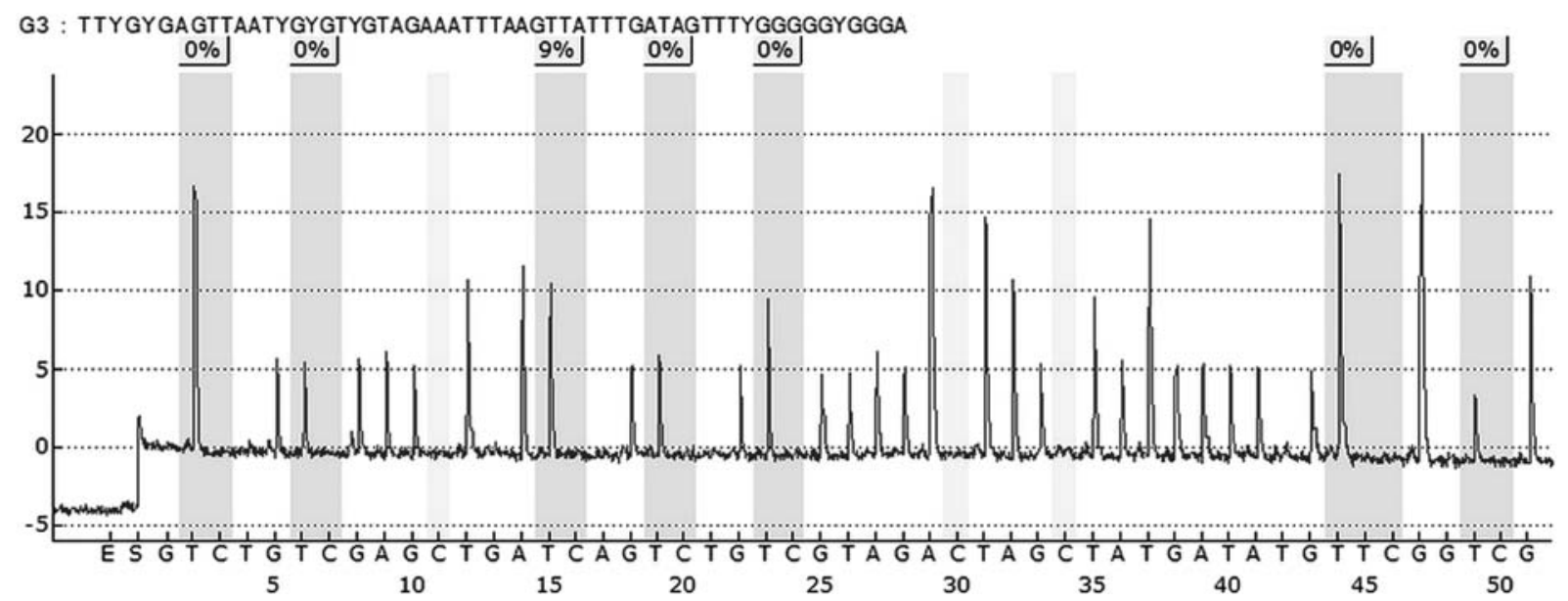

Figure 3. Typical pyrogram showing the sequence analyzed in Amp 3 in the PTCH gene by the Amp 3-Py1 assay.

samples, matched from each patient. None of these 32 tissue samples showed any signs of methylation in any of the eight Pyrosequencing assays.

\section{Discussion}

We optimized our PCR and Pyrosequencing protocols (Table I and Figs. 2-7) with gDNA originating from human leukocytes. This is a cell type that turned out to be unmethylated, as expected, on all $\mathrm{CpG}$ sites studied in the $\mathrm{PTCH}$ promoter (Figs. 2-7). Unexpectedly, none of the 22 squamous cell cervical cancer or 5 ovarian cancer tissues tested, showed methylated $\mathrm{CpG}$ sites in any of the eight PTCH assays. Therefore, $P$ TCH promoter methylation is probably not a high-prevalence event in squamous cell cervical cancer or ovarian cancer. This is not a surprising finding, since it has been shown that cervical cancer samples usually show increased expression of PTCH protein (12), and the same is true for ovarian cancer (20), although $\mathrm{LOH}$ of the $\mathrm{PTCH}$ region has been associated with some types of ovarian cancer (21). Extended applications of these newly-developed assays to larger series of cancer tissues from other cell types will be needed to clarify the extent and role of PTCH promoter methylation in other human cancers.

The current and perhaps most popular methodology to study DNA methylation, 'methylation specific' PCR (often featured in microarrays), has the limitation of only assaying the methylation status of a few $\mathrm{CpG}$ sites that interfere with PCR-primer binding. This technique only gives a qualitative indication if the sites are methylated or not; like all 'allele specific' PCR methods, the judgment of the presence or absence of a band on an agarose gel is largely a matter of the combination of the number of PCR optimization experiments made and subjective analysis of gel electrophoresis bands. We believe that these drawbacks are a real cause of concern, which may have stalled progress in the understanding of the role of DNA methylation in clinical cancer research. Compared to 'methylation specific' PCR, Pyrosequencing technology and Pyro Q-CpG Software v. 1.0.9 automatically generate a quantitative measure in percent methylation for each $\mathrm{CpG}$ site in the studied sequence. This methodology allows the detection of partially methylated $\mathrm{CpG}$ sites; therefore, yielding a more accurate picture of how the methylation is distributed throughout the promoter region than the qualitative assays. 

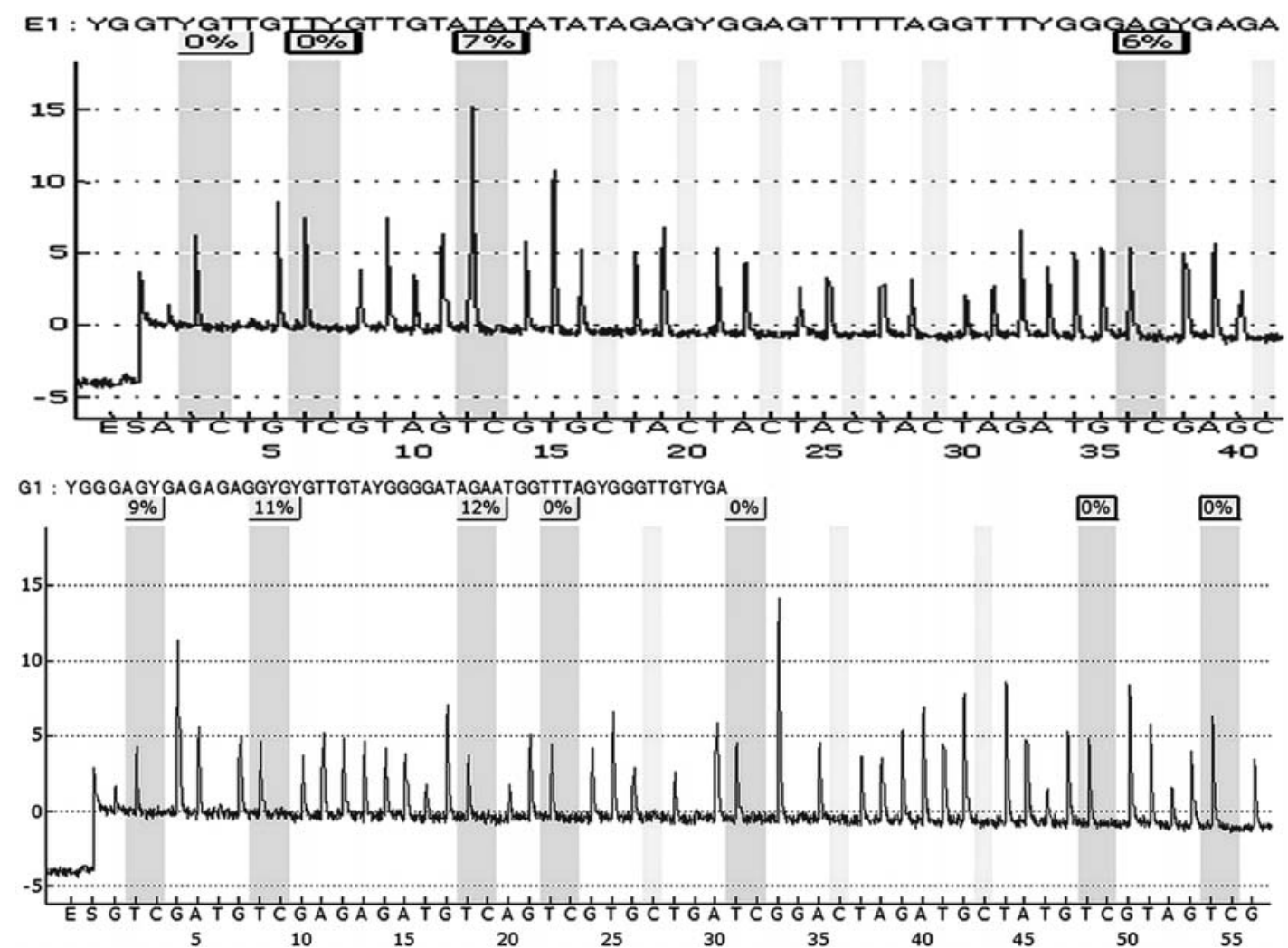

Figure 4. Typical pyrograms showing the sequences analyzed in Amp 4 in the PTCH gene. This amplicon was divided into two different Pyrosequencing assays, Amp4-Py1 (upper panel) and Amp4-Py2 (lower panel).

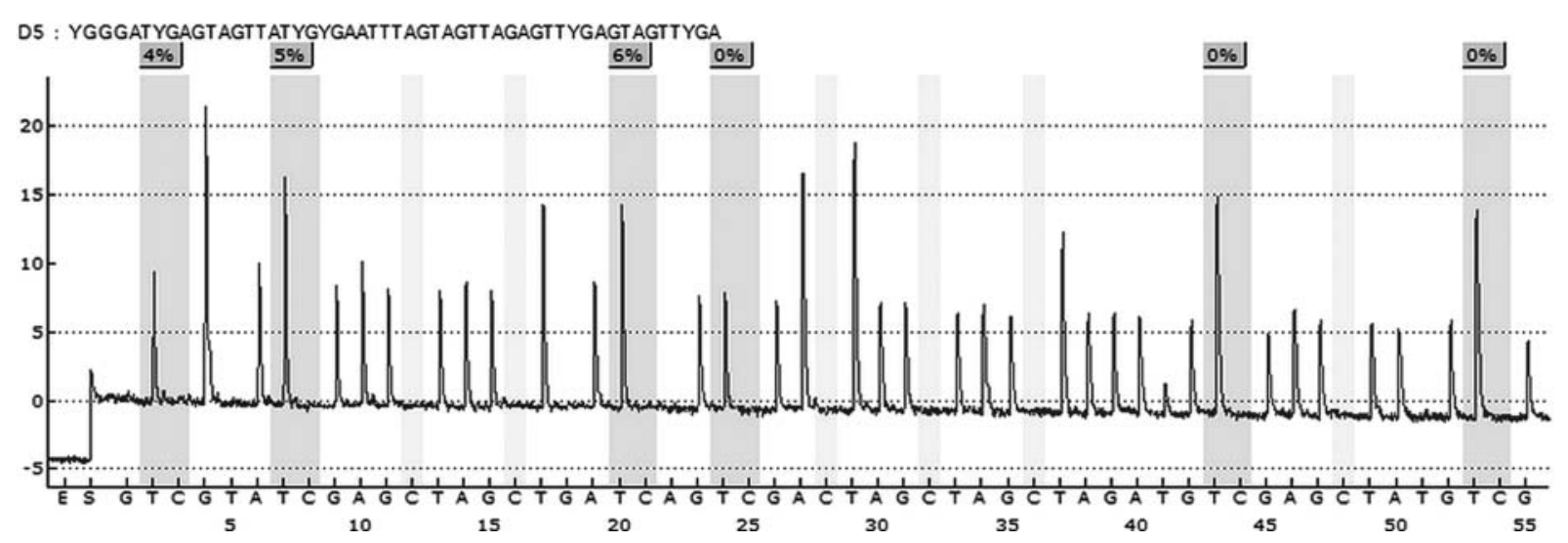

Figure 5. Typical pyrogram showing the sequence analyzed in Amp 5 in the $P T C H$ gene by the Amp 5-Py1 assay.

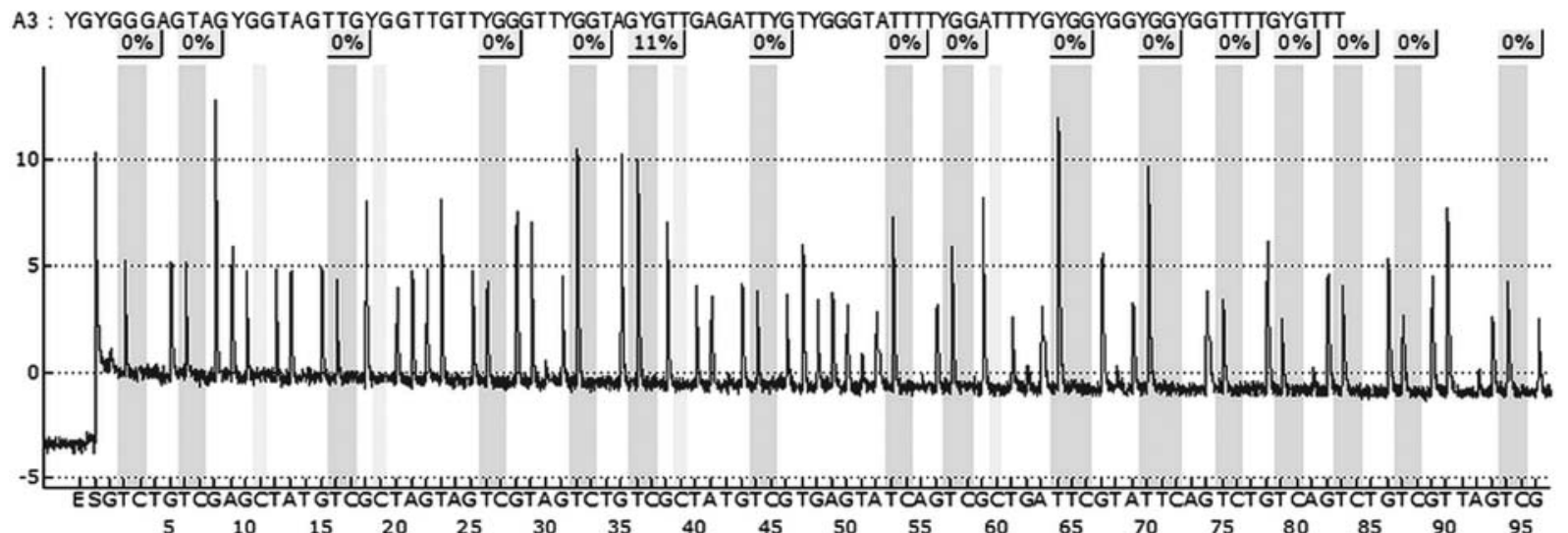

Figure 6. Typical pyrogram showing the sequence analyzed in Amp 6 in the PTCH gene by the Amp 6-Py1 assay. 

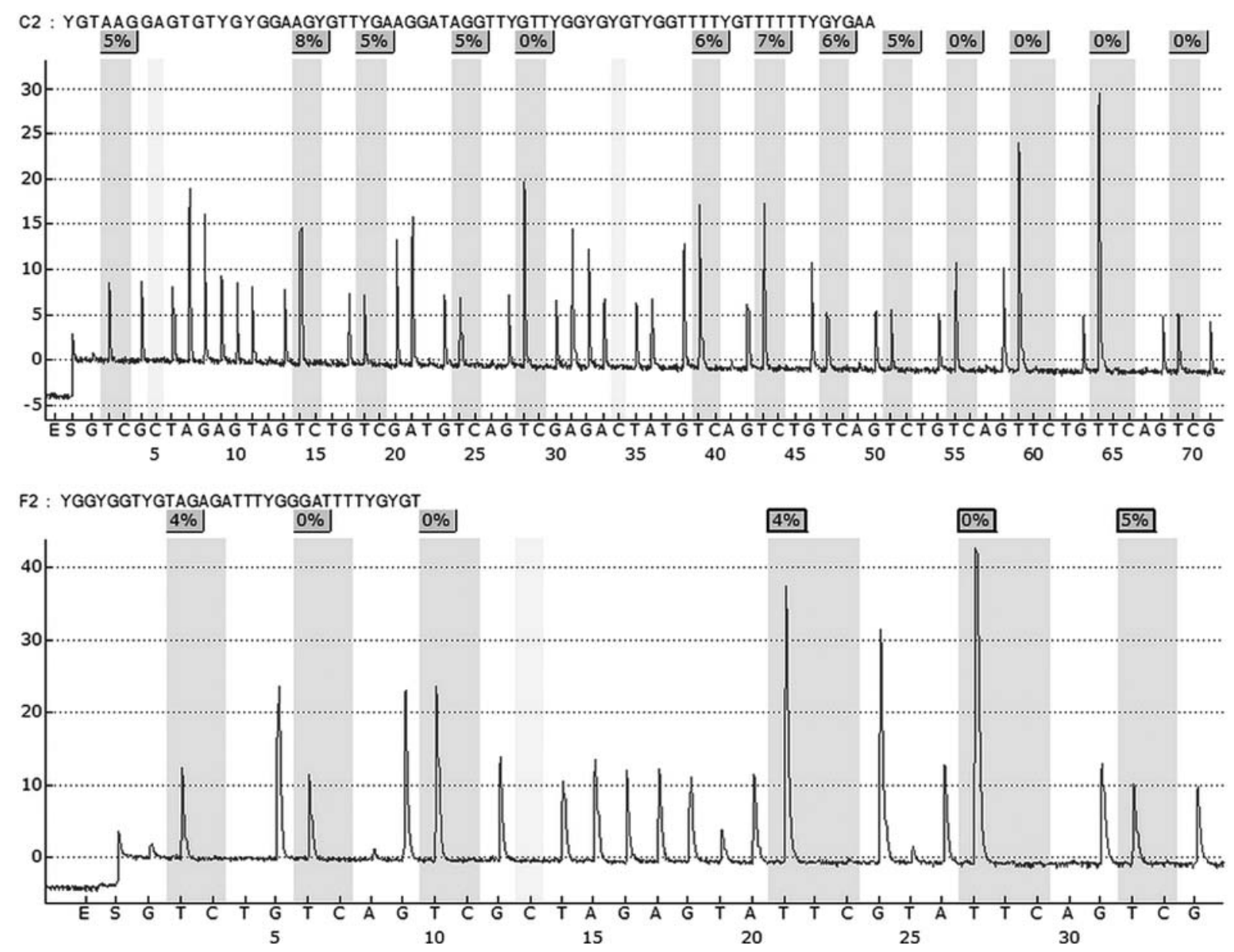

Figure 7. Typical pyrograms showing the sequences analyzed in Amp 7 of the $P T C H$ gene. This amplicon was divided into two different Pyrosequencing assays, Amp7-Py1 (upper panel) and Amp7-Py2 (lower panel).

Analysis of $\mathrm{CpG}$ sites in the $\mathrm{PTCH}$ gene is unusually challenging owing to method development aspects, but only $36 \mathrm{CpG}$ sites in the $\mathrm{PTCH}$ promoter remained uncovered by our assays designed for regions 1 and 2, recently studied by conventional DNA sequencing (7) and region 3, previously considered unfeasible to amplify. Pyrosequencing assays could not be developed for region 4 due to the extensive amount of $\mathrm{CpG}$ sites, including 63 sites densely grouped within a 456-bp region (Fig. 1, lines 15-20 in ref. 7): there were no stretches of unique, CpG-free sequences where PCR primers could bind; therefore, it could not be split into smaller amplicons. We also attempted to analyze this $456 \mathrm{bp}$ amplicon directly by Pyrosequencing, but as expected, it turned out to be too long to analyze; optimal amplicon length for this technique is around 150-200 bp. Therefore, CpGs in that region still await to be quantified by other means.

In conclusion, we developed eight Pyrosequencing assays to quantify the methylation of promoter regions 1,2 and the previously unanalyzed region 3 of the $P T C H$ gene. Our data suggest that methylation of the $P T C H$ promoter is not a high-prevalence feature of squamous cell cervical cancer or ovarian cancer. Clinical applications of the novel DNA methylation assays, in order to characterize the conditions associated with PTCH promoter methylation in various cancer forms, will be the object of our further studies.

\section{References}

1. Beachy PA, Karhadkar SS and Berman DM: Tissue repair and stem cell renewal in carcinogenesis. Nature 432: 324-331, 2004.

2. Hahn H, Wicking C, Zaphiropoulous PG, Gailani MR, Shanley S, Chidambaram A, Vorechovsky I, Holmberg E, Unden AB, Gillies S, Negus K, Smyth I, Pressman C, Leffell DJ, Gerrard B, Goldstein AM, Dean M, Toftgard R, Chenevix-Trench G, Wainwright $\mathrm{B}$ and Bale AE: Mutations of the human homolog of Drosophila patched in the nevoid basal cell carcinoma syndrome. Cell 85: 841-851, 1996.

3. Denef N, Neubuser D, Perez L and Cohen SM: Hedgehog induces opposite changes in turnover and subcellular localization of patched and smoothened. Cell 102: 521-531, 2000.

4. Taipale J, Cooper MK, Maiti T and Beachy PA: Patched acts catalytically to suppress the activity of Smoothened. Nature 418: 892-897, 2002.

5. Ruiz i Altaba A: Gli proteins and Hedgehog signaling: development and cancer. Trends Genet 15: 418-425, 1999.

6. Johnson RL, Rothman AL, Xie J, Goodrich LV, Bare JW, Bonifas JM, Quinn AG, Myers RM, Cox DR, Epstein EH Jr and Scott MP: Human homolog of patched, a candidate gene for the basal cell nevus syndrome. Science 272: 1668-1671, 1996.

7. Cretnik M, Musani V, Oreskovic S, Leovic D and Levanat S: The Patched gene is epigenetically regulated in ovarian dermoids and fibromas, but not in basocellular carcinomas. Int J Mol Med 19: 875-883, 2007.

8. Wolf I, Bose S, Desmond JC, Lin BT, Williamson EA, Karlan BY and Koeffler HP: Unmasking of epigenetically silenced genes reveals DNA promoter methylation and reduced expression of PTCH in breast cancer. Breast Cancer Res Treat 105: 139-155, 2007. 
9. Hahn H, Christiansen J, Wicking C, Zaphiropoulos PG, Chidambaram A, Gerrard B, Vorechovsky I, Bale AE, Toftgard R, Dean $\mathrm{M}$ and Wainwright B: A mammalian patched homolog is expressed in target tissues of sonic hedgehog and maps to a region associated with developmental abnormalities. J Biol Chem 271: 12125-12128, 1996

10. Berman DM, Karhadkar SS, Hallahan AR, Pritchard JI, Eberhart CG, Watkins DN, Chen JK, Cooper MK, Taipale J, Olson JM and Beachy PA: Medulloblastoma growth inhibition by hedgehog pathway blockade. Science 297: 1559-1561, 2002 .

11. Toyota M, Kopecky KJ, Toyota MO, Jair KW, Willman CL and Issa JP: Methylation profiling in acute myeloid leukemia. Blood 97: 2823-2829, 2001.

12. Xuan YH, Jung HS, Choi YL, Shin YK, Kim HJ, Kim KH, Kim WJ, Lee YJ and Kim SH: Enhanced expression of hedgehog signaling molecules in squamous cell carcinoma of uterine cervix and its precursor lesions. Mod Pathol 19: 1139-1147, 2006.

13. Gailani MR, Stahle-Backdahl M, Leffell DJ, Glynn M, Zaphiropoulos PG, Pressman C, Unden AB, Dean M, Brash DE, Bale AE and Toftgard R: The role of the human homologue of Drosophila patched in sporadic basal cell carcinomas. Nat Genet 14: 78-81, 1996

14. Bird A: DNA methylation patterns and epigenetic memory. Genes Dev 16: 6-21, 2002.

15. Das PM and Singal R: DNA methylation and cancer. J Clin Oncol 22: 4632-4642, 2004
16. Nagao K, Toyoda M, Takeuchi-Inoue K, Fujii K, Yamada M and Miyashita T: Identification and characterization of multiple isoforms of a murine and human tumor suppressor, patched, having distinct first exons. Genomics 85: 462-471, 2005.

17. Ågren M, Kogerman P, Kleman MI, Wessling M and Toftgård R: Expression of the PTCH1 tumor suppressor gene is regulated by alternative promoters and a single functional Gli-binding site. Gene 330: 101-114, 2004.

18. Kogerman P, Krause D, Rahnama F, Kogerman L, Unden AB, Zaphiropoulos PG and Toftgard R: Alternative first exons of $\mathrm{PTCH} 1$ are differentially regulated in vivo and may confer different functions to the PTCH1 protein. Oncogene 21: 6007-6016, 2002.

19. Royo JL, Hidalgo M and Ruiz A: Pyrosequencing protocol using a universal biotinylated primer for mutation detection and SNP genotyping. Nat Protoc 2: 1734-1739, 2007.

20. Chen X, Horiuchi A, Kikuchi N, Osada R, Yoshida J, Shiozawa T and Konishi I: Hedgehog signal pathway is activated in ovarian carcinoma, correlating with cell proliferation: its inhibition leads to growth suppression and apoptosis. Cancer Sci 98: 68-76, 2007.

21. Tsuji T, Catasus L and Prat J: Is loss of heterozygosity at 9q22.3 (PTCH gene) and 19p13.3 (STK11 gene) involved in the pathogenesis of ovarian stromal tumors? Hum Pathol 36: 792-796, 2005 . 